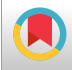

\title{
Knowledge Translation at Lorestan University of Medical Sciences: Evidence from Iran
}

\author{
Mohammad Hasan Imani-Nasab (iD) ${ }^{1}$, Soraya Nouraei Motlagh (iid ${ }^{1}$, Peivand Bastani $\mathbb{B}^{2}$, Mehdi Birjandi \\ (iD) ${ }^{1}$, Katayoon Bakhtiar (iD ${ }^{1}$ and Mahnaz Samadbeik (iD ${ }^{3,}{ }^{*}$ \\ ${ }^{1}$ Social Determinants of Health Research Center, Lorestan University of Medical Sciences, Khorramabad, Iran \\ ${ }^{2}$ Health Human Resources Research Center, School of Management and Medical Informatics, Shiraz University of Medical Sciences, Shiraz, Iran \\ ${ }^{3}$ Social Determinants of Health Research Center, Lorestan University of Medical Sciences, Khorramabad, Iran \\ "Corresponding author: Social Determinants of Health Research Center, Lorestan University of Medical Sciences, Khorramabad, Iran. Tel: +98-6633120172, Email: \\ mahbeik@yahoo.com
}

Received 2019 February 10; Revised 2019 December 18; Accepted 2020 January 27.

\begin{abstract}
Background: Health systems around the world are encountered with the challenge of filling the gap between knowledge and practice.

Objectives: This study aimed to investigate the status of knowledge translation at Lorestan University of Medical Sciences, Iran.

Methods: This cross-sectional study was conducted in 2017. For data collection, the knowledge translation self-assessment tool for research institutes was used. Data analysis was conducted based on the four-dimensional and seven-dimensional structures of the tool. The data were analyzed using descriptive and analytical statistics.

Results: The overall status of knowledge translation was at an average level with a mean score of 2.13 out of total score 5 . The studied university acquired a mean score of 2.41 (good level) from maximum score 4.22 in the knowledge generation dimension and a mean score of 1.70 (weak level) from maximum score 3.50 in the dimension of promoting the use of evidence. Comparison of the mean scores of knowledge translation and its dimensions did not show any significant association with the faculty members' characteristics (age, work experience, gender, education level, academic rank, and school).

Conclusions: Considering the overall level of knowledge translation and the poor level in some dimensions, it is suggested that the studied university puts the periodic self-assessment of knowledge translation on the agenda and designs and implements the improvement interventions based on the self-assessments.
\end{abstract}

Keywords: Knowledge Translation, Knowledge Transfer, Medical Faculty, Iran

\section{Background}

Health systems around the world are encountered with the challenge of filling the gap between knowledge and practice $(1,2)$. In Iran, the universities of medical sciences (UsMS) are under the governance of the Ministry of Health and Medical Education. This structure has led to the integration of teaching, research, and service delivery at UsMS. Therefore, it is expected that knowledge translation (KT) is made more efficiently $(3,4)$. In recent years, the number of research projects and articles of Iranian UsMS, including Lorestan University of Medical Sciences (LUMS), has increased. Therefore, the optimal and practical use of research evidence is one of the important issues to be considered.

\section{Objectives}

This study aimed to assess and compare the status of KT at LUMS as a case study. The present study results can help identify the weaknesses and provide an opportunity to design improvement plans for KT at Iranian UsMS, particularly LUMS.

\section{Methods}

This cross-sectional study was conducted in 2017 at LUMS. The statistical population included the LUMS faculty members. The stratified sampling method proportional to the size was used. First, each school was considered a stratum; then, the faculty members were selected randomly from each stratum. The number of samples was calculated 
to be at least 80 people. The KT "Self-Assessment Tool for Research Institutes" (SATORI) was used to collect data (5). Its dual structure (four-dimensional and seven-dimensional) improves the understanding of the status of KT in research institutes. Data were collected by the in-person distribution of questionnaires among the subjects. Knowledge translation status was divided into three levels of weak (1 - 1.87), moderate (1.88 - 2.37), and good (2.38 - 5) based on the mean score of each dimension and the total score of KT. The data were analyzed using descriptive and analytical statistics (independent $t$ tests, Pearson and Spearman correlation coefficients, ANOVA, and MANOVA) via SPSS-20 software.

\section{Results}

Table 1 indicates the mean scores of KT in the fourdimensional and seven-dimensional structures. The results showed that the overall KT status in the two structures was 2.13 , indicating a moderate level. In the fourdimensional structure (FDS), the "knowledge generation" dimension had the highest score as 2.41 (good level) and the dimension of "promoting the use of evidence" had the lowest score as 1.70 (weak level). In the seven-dimensional structure (SDS), the dimension of "research quality and timeliness" with a mean score of 2.58 (good level) had the highest score and the dimensions of "evaluation and promotion of the use of evidence" and "interaction with the research users" each with a mean score of 1.76 (weak level) earned the lowest scores.

Table 1. Status of Knowledge Translation at Lorestan University of Medical Sciences Based on the Four-Dimensional Structure and Seven-Dimensional Structure

\begin{tabular}{l|c|l|c}
\hline FDS & Mean \pm SD & SDS & Mean \pm SD \\
\hline $\begin{array}{l}\text { Research } \\
\text { question }\end{array}$ & $1.91 \pm 0.58$ & Priority setting & $2.04 \pm 0.75$ \\
\cline { 3 - 4 } & $\begin{array}{l}\text { Research quality and } \\
\text { timeliness }\end{array}$ & $2.52 \pm 0.64$ \\
\hline \multirow{2}{*}{$\begin{array}{l}\text { Knowledge } \\
\text { generation }\end{array}$} & $2.41 \pm 0.61$ & $\begin{array}{l}\text { Researchers' KT } \\
\text { capacities }\end{array}$ & $2.30 \pm 0.74$ \\
\cline { 3 - 4 } & $\begin{array}{l}\text { Interaction with research } \\
\text { users }\end{array}$ & $1.76 \pm 0.6$ \\
\cline { 3 - 4 } & $\begin{array}{l}\text { Facilities and } \\
\text { prerequisites of KT }\end{array}$ & $2.15 \pm 0.58$ \\
\hline $\begin{array}{l}\text { Knowledge } \\
\text { transfer }\end{array}$ & $2.20 \pm 0.59$ & $\begin{array}{l}\text { Processes and regulations } \\
\text { supporting KT }\end{array}$ & $2.24 \pm 0.55$ \\
\hline $\begin{array}{l}\text { Promoting } \\
\text { evidence } \\
\text { utilization }\end{array}$ & $1.71 \pm 0.62$ & $\begin{array}{l}\text { Promoting and } \\
\text { evaluating the use of } \\
\text { evidence }\end{array}$ & $1.76 \pm 0.62$ \\
\hline Total & $2.13 \pm 0.51$ & Total & $2.13 \pm 0.50$ \\
\hline
\end{tabular}

The results of multivariate analysis of variance showed that the variables of school $(F=1.49$, Wilk's Lambda $=0.369$ and $\mathrm{P}=0.07)$, sex $(\mathrm{F}=0.438$, Wilk's Lambda $=0.921$ and $\mathrm{P}=$ 0.87), native status ( $\mathrm{F}=1.154$, Wilk's Lambda $=0.817$ and $\mathrm{P}=$ 0.353), academic rank ( $\mathrm{F}=1.31$, Wilk's Lambda $=0.634, \mathrm{P}=$ $0.22)$, and education level $(\mathrm{F}=1.64$, Wilk's Lambda $=0.431$ and $\mathrm{P}=0.053$ ) were not significant at the 0.05 level. The comparison of the total mean score of KT in terms of demographic and academic characteristics did not show any significant differences between FDS (Table 2) and SDS regarding the participants' age, work experience, gender, native status, education level, academic rank, and school (P> 0.05).

The test of the equality of variances among the five schools indicated heterogeneous variances in the dimensions of research question $(\mathrm{P}=0.025)$, knowledge generation $(\mathrm{P}=0.042)$, and promoting the use of evidence ( $\mathrm{P}$ $=0.001$ ); thus, the assumption of unequal variances was accepted at the level of $\mathrm{P}=0.05$. However, the variances were homogeneous in the knowledge transfer dimension $(P>0.05)$. Nevertheless, the total mean score of KT was the highest in the school of medicine (2.21) and the mean score was the lowest (1.94) in the School of Health and Nutrition. Furthermore, the total mean score and the mean score of each of the four dimensions of KT did not show any significant association with having or not having a research center $(P>0.05)$. Moreover, the total mean score and the mean score of each of the four dimensions of KT did not show any significant association with the number of faculty members with different academic ranks ( $\mathrm{P}>0.05)$.

\section{Discussion}

The present study indicated that the status of KT at LUMS was at a moderate level. The findings of studies on the status of KT at other Iranian UsMS show that the status of KT was not favorable despite the significant number of published articles (3, 6-9). In the health system of Iran, in which the UsMS offer health, education, and research services, there is a better chance for a closer relationship between knowledge producers (supply-side) and decisionmakers (demand-side) (10). In the present study, the status of KT was at a good level in the FDS regarding "knowledge generation" and in the SDS regarding "research quality and timeliness". Similar studies conducted at the Qazvin University of Medical Sciences (QUMS) and the research centers of Isfahan University of Medical Sciences demonstrated that the highest mean scores were related to the dimensions of "production of evidence for use in decisionmaking" and "knowledge generation" $(3,11)$. In the study of the status of KT in the health research centers of the Eastern Mediterranean countries (2014) and the UsMS affiliated to the Ministry of Health (2013), the "research quality and timeliness" obtained the highest scores $(6,7)$. Therefore, 


\begin{tabular}{|c|c|c|c|c|c|c|}
\hline \multirow{2}{*}{$\begin{array}{l}\text { Demographic and } \\
\text { Academic } \\
\text { Characteristics }\end{array}$} & \multicolumn{5}{|c|}{ Mean \pm SD } & \multirow{2}{*}{ P Value } \\
\hline & Research Question & $\begin{array}{l}\text { Knowledge } \\
\text { Generation }\end{array}$ & Knowledge Transfer & $\begin{array}{l}\text { Promoting } \\
\text { Evidence } \\
\text { Utilization }\end{array}$ & Total & \\
\hline \multicolumn{7}{|l|}{ Gender } \\
\hline Male & $1.94 \pm 0.58$ & $2.41 \pm 0.57$ & $2.24 \pm 0.55$ & $1.72 \pm 0.61$ & $2.16 \pm 0.56$ & 0.57 \\
\hline Female & $1.88 \pm 0.58$ & $2.42 \pm 0.70$ & $2.14 \pm 0.66$ & $1.68 \pm 0.66$ & $2.09 \pm 0.58$ & \\
\hline \multicolumn{7}{|l|}{ Native status } \\
\hline Native & $1.93 \pm 0.51$ & $2.44 \pm 0.56$ & $2.28 \pm 0.56$ & $1.67 \pm 0.58$ & $2.18 \pm 0.47$ & 0.27 \\
\hline Non-native & $1.82 \pm 0.66$ & $2.34 \pm 0.72$ & $2.06 \pm 0.65$ & $1.64 \pm 0.64$ & $2.03 \pm 0.57$ & \\
\hline \multicolumn{7}{|l|}{ Education level } \\
\hline M.Sc. & $2 \pm 0.51$ & $2.72 \pm 0.81$ & $2.60 \pm 0.44$ & $1.65 \pm 0.70$ & $2.41 \pm 0.57$ & 0.49 \\
\hline Ph.D. & $2.08 \pm 0.73$ & $2.67 \pm 0.62$ & $2.26 \pm 0.51$ & $1.80 \pm 0.76$ & $2.26 \pm 0.55$ & \\
\hline $\begin{array}{l}\text { Medical } \\
\text { specialty }\end{array}$ & $1.92 \pm 0.52$ & $2.40 \pm 0.65$ & $2.19 \pm 0.60$ & $1.66 \pm 0.54$ & $2.12 \pm 0.52$ & \\
\hline Fellowship & $1.87 \pm 0.63$ & $2.19 \pm 0.43$ & $2.12 \pm 0.67$ & $1.73 \pm 0.69$ & $2.05 \pm 0.56$ & \\
\hline \multicolumn{7}{|l|}{ School } \\
\hline Medicine & $2.03 \pm 0.60$ & $2.19 \pm 0.43$ & $2.26 \pm 0.55$ & $1.71 \pm 0.47$ & $2.21 \pm 0.47$ & 0.65 \\
\hline Dentistry & $1.97 \pm 0.72$ & $2.31 \pm 0.59$ & $2.14 \pm 0.71$ & $2.15 \pm 0.94$ & $2.13 \pm 0.63$ & \\
\hline $\begin{array}{l}\text { Nursing and } \\
\text { midwifery }\end{array}$ & $1.98 \pm 0.43$ & $2.46 \pm 0.73$ & $2.25 \pm 0.71$ & $1.62 \pm 0.67$ & $2.17 \pm 0.62$ & \\
\hline Paramedicine & $1.40 \pm 0.08$ & $2.44 \pm 1.25$ & $2.33 \pm 0.63$ & $1.37 \pm 0.43$ & $2.05 \pm 0.50$ & \\
\hline $\begin{array}{l}\text { health and } \\
\text { nutrition }\end{array}$ & $1.70 \pm 0.35$ & $2.14 \pm 0.57$ & $2.05 \pm 0.55$ & $1.56 \pm 0.58$ & $1.94 \pm 0.44$ & \\
\hline \multicolumn{7}{|l|}{ Academic rank } \\
\hline Instructor & $1.86 \pm 0.47$ & $2.19 \pm 0.62$ & $2.29 \pm 0.53$ & $1.74 \pm 0.53$ & $2.12 \pm 0.40$ & 0.69 \\
\hline $\begin{array}{l}\text { Assistant } \\
\text { Professor }\end{array}$ & $1.87 \pm 0.59$ & $2.42 \pm 0.60$ & $2.14 \pm 0.64$ & $1.67 \pm 0.59$ & $2.09 \pm 0.55$ & \\
\hline $\begin{array}{l}\text { Associate } \\
\text { Professor and } \\
\text { Professor }\end{array}$ & $2.08 \pm 0.64$ & $2.58 \pm 0.64$ & $2.24 \pm 0.57$ & $1.75 \pm 0.75$ & $2.22 \pm 0.55$ & \\
\hline
\end{tabular}

given the similarities in the status of KT in the universities and the countries of the Eastern Mediterranean region, the Regional Office of the World Health Organization (EMRO) can play an important role in supporting KT through directing the countries of the region toward this important issue and providing strategic guidance (6).

The findings of this study revealed that the KT status of LUMS was weak regarding "promoting the use of evidence" in the FDS and SDS and regarding "interaction with users of research" in the SDS. These dimensions had also lower scores in other similar studies. However, the main weakness of the KT in these studies was on the topics of "research question" and "priority setting" and the researchers' individual interests were considered the only reason for choosing a research question (3, 7, 11-13). In the present study, "research question" in the FDS and "prior- ity setting" in the SDS were at a moderate level. Therefore, research topics should be defined as a result of the researchers' interaction with the stakeholders and based on the audience's needs. Also, KT should be considered one of the educational needs for the educational and research centers of excellence in Iran (14).

Based on the results of this study, there was no significant association between the KT scores and demographic characteristics (gender and education level). Similar results were obtained in a study conducted at QUMS (11); however, at the Tehran University of Medical Sciences, the KT score decreased with the increase of work experience (3). Also, the influential factors such as male gender, clinical sciences research, and having administrative responsibility could increase the researchers' KT activities score at the Golestan University of Medical Sciences (15). 
It is suggested that the self-assessment of KT be carried out periodically by UsMS and necessary interventions be applied based on the self-assessment results. Furthermore, the allocation of a research budget to KT can be effective in improving the status of KT at UsMS. Applying encouraging policies for researchers to transfer the research findings to users and considering incentives for policymakers to support the use of evidence in the decision-making cycle. It is suggested that UsMS and their research centers have a serious and ongoing relationship with stakeholders to determine research topics and prioritize them. In this regard, conducting customized research and attracting grants from external resources can contribute to an effective relationship with stakeholders and can lead to better research achievements.

\section{Acknowledgments}

The present study was funded by the Research and Technology Deputy of Lorestan University of Medical Sciences.

\section{Footnotes}

Authors' Contribution: Data analysis: Mehdi Birjandi. Drafting of the manuscript: Mohammad Hasan ImaniNasab and Mahnaz Samadbeik. Critical revision of the manuscript for important intellectual content: Mohammad Hasan Imani-Nasab, Soraya Nouraei Motlagh, Peivand Bastani, Mehdi Birjandi, Katayoon Bakhtiar, and Mahnaz Samadbeik.

Conflict of Interests: There was no conflict of interest among the authors.

\section{Ethical Approval: IR.LUMS.REC.1396.1988.}

Funding/Support: Lorestan Universities of Medical Sciences (LUMS) funded the study.

Informed Consent: Informed consent was obtained from all participants in the study.

\section{References}

1. Weaver CA, Warren JJ, Delaney C; International Medical Informatics Association; Nursing Informatics Special Interest Group; EvidenceBased Practice Working Group. Bedside, classroom and bench: collaborative strategies to generate evidence-based knowledge for nursing practice. Int J Med Inform. 2005;74(11-12):989-99. doi: 10.1016/j.ijmedinf.2005.07.003. [PubMed:16084124].

2. Straus SE, Graham ID, Mazmanian PE. Knowledge translation: Resolving the confusion. J Contin Educ Health Prof. 2006;26(1):3-4. doi: 10.1002/chp.45. [PubMed: 16557515].

3. Nedjat S, Majdzadeh R, Gholami J, Nedjat S, Maleki K, Qorbani M, et al. Knowledge transfer in Tehran University of Medical Sciences: An academic example of a developing country. Implement Sci. 2008;3:39. doi: 10.1186/1748-5908-3-39. [PubMed: 18727835]. [PubMed Central: PMC2538542].

4. Marandi A. Integrating medical education and health services: The Iranian experience. Med Educ. 1996;30(1):4-8. doi: 10.1111/j.13652923.1996.tb00709.x. [PubMed: 8736181].

5. Gholami J, Majdzadeh R, Nedjat S, Nedjat S, Maleki K, Ashoorkhani $M$, et al. How should we assess knowledge translation in research organizations; designing a knowledge translation self-assessment tool for research institutes (SATORI). Health Res Policy Syst. 2011;9:10 doi: 10.1186/1478-4505-9-10. [PubMed: 21342517]. [PubMed Central: PMC3053266].

6. Maleki K, Hamadeh RR, Gholami J, Mandil A, Hamid S, Butt ZA, et al. The knowledge translation status in selected Eastern-Mediterranean universities and research institutes. PLoS One. 2014;9(9). e103732. doi 10.1371/journal.pone.0103732. [PubMed: 25197834]. [PubMed Central: PMC4157749].

7. Gholami J, Ahghari S, Motevalian A, Yousefinejad V, Moradi G, Keshtkar A, et al. Knowledge translation in Iranian universities: Need for serious interventions. Health Res Policy Syst. 2013;11:43. doi: 10.1186/1478-4505-11-43. [PubMed: 24225146]. [PubMed Central: PMC3835863].

8. Majdzadeh R, Nedjat S, Gholami J, Nedjat S, Maleki K, Qorbani M, et al. Research collaboration in Tehran University of Medical Sciences: Two decades after integration. Health Res Policy Syst. 2009;7:8 doi: 10.1186/1478-4505-7-8. [PubMed: 19386131]. [PubMed Central: PMC2679006].

9. Zamanzadeh V, Namadi Vosoughi M. Nursing research direction in Iran, challenges and solutions: An integrative review. J Urmia Nurs MidwifFac. 2018;16(4):234-47.

10. Majdzadeh R, Nedjat S, Fotouhi A, Malekafzali H. Iran's approach to knowledge translation. Iran J Public Health. 2009;38(Suppl 1):58-62.

11. Hosseini MA, Kermanshahani F, Ahmadi S, Sadeghi T, Mirbaha S, Safarizadeh M. A study on status of knowledge translation in Qazvin University of Medical Sciences. Res Med Educ. 2015;7(2):52-60. doi: 10.18869/acadpub.rme.7.2.52

12. Ferdosi M, Alavi SS. Evaluation of research utilization in Isfahan University of Medical Sciences by knowledge transfer and exchange criteria. Health Inf Manage. 2011;7(S):525-32.

13. Nedjat S, Sadighi J, Gholami J, Majdzadeh R. Self-assessment in research organizations. Payesh J. 2008;7:259-68.

14. Damari B, Kamrava K, Kazemi-Asl S, Momtaz-Manesh N, VosooghMoghaddam A, Mirzaei H. Determining educational needs of educational and research centers of excellence: Road map of scientific and educational centers of excellence in medical sciences. Commun Health. 2018;5(1):87-93.

15. Asayesh H, Qorbani M, Borghei A, Rezapour A, Mohammadi Y, Mansourian $\mathrm{M}$, et al. The validity of researchers self evaluation about their own activities in knowledge translation (KT).JPayavard Salamat. 2014;7(5):421-31. 